\title{
Análisis estadístico de la influencia del virus del papiloma humano en el desarrollo del carcinoma vesical
}

\author{
Jiménez Pacheco A, Martínez Torres JL, Pareja Vilchez M, Arrabal Martín M, \\ Valle Díaz de la Guardia F, López León V, Zuluaga Gómez A.
}

Servicio de Urología. Hospital Universitario San Cecilio. Granada.

Actas Urol Esp. 2007;31(5):469-476

\section{RESUMEN}

ANÁLISIS ESTADÍSTICO DE LA INFLUENCIA DEL VIRUS DEL PAPILOMA HUMANO EN EL DESARROLLO DEL CARCINOMA VESICAL

Introducción: El carcinoma de vejiga es una enfermedad importante por su morbi-mortalidad y su multifactorialidad. Actualmente, entre los posibles agentes etiológicos que se han señalado, se encuentra la infección por el virus del papiloma humano (VPH). El objetivo del estudio es analizar, mediante la realización de un meta-análisis, la relación existente entre el cáncer vesical y la infección por el virus del papiloma humano.

Material y métodos: Realizamos una búsqueda en la base de datos electrónica MEDLINE de los artículos publicados hasta septiembre del 2004 que relacionan la infección del VPH con los tumores vesicales. De los 414 artículos listados, seleccionamos 38 artículos.

Resultados: Los artículos se clasificaron en dos grupos, según empleen o no métodos basados en la detección del ADN. En los artículos basados en la detección del ADN, resultó que la proporción global de los casos que tuvieron contacto con el virus, a través de la detección del genoma fue del 19,4\% (IC 95\%: 0,160-0,228). Del total de estudios basados en la detección del ADN se seleccionaron 8, por mostrar un grupo control definido, en los cuales, se investigó la OR. Si combinamos las ORs, obtenemos una OR estimada de 3,2 (IC al 95\% de 1,19 a 8,60) y una p=0,02.

Conclusiones: La mayor parte de estos estudios pusieron de manifiesto la relación planteada al inicio del estudio. Aunque la mayoría carecían de un grupo control definido, es posible analizar el valor de la Odds ratio global debido al comportamiento homogéneo de los estudios con casos y controles bien definidos. Esto demostró una asociación entre VPH y el cáncer de la vejiga.

Palabras clave: Carcinoma vesical. Papilomavirus. Reacción en cadena de la polimerasa (PCR).

\section{ABSTRACT \\ STATISTICAL ANALYSIS OF THE INFLUENCE OF THE VIRUS OF PAPILOMA HUMAN IN THE DEVELOPMENT OF THE VESICAL CARCINOMA}

Introduction: The bladder cancer is an important disease by its morbi-mortality and its multifactorialidad. At the moment, between the possible aetiology agents that they have been indicated is the infection by the virus of papilloma human (VPH). The objective study is to analyse, by meta-analysis, the relationship between bladder cancer and infection by human papillomavirus

Material and methods: We made a search in the electronic data base MEDLINE of the articles published until September of the 2004 that relate the infection of the VPH to the bladder tumors. Of 414 listed articles, we selected 38 articles.

Results: The articles were classified in two groups, according to they use or non methods based on the detection of the DNA. In articles based on the detection of the DNA, it was that the global proportion from the cases that had contact with the virus, through the detection of the genome was of the $19.4 \%$ (95\% CI 0.160 to 0.228 ). Of the total of studies based on the detection of the DNA 8 were selected, to show to a group defined control, in which, the OR was investigated. If we combined the ORs, we obtain an OR estimation of 3.2 (95\% CI 1.19 to 8.60) and p=0.02.

Conclusions: Most of these studies showed the relation rose at the beginning of the study. Although the majority lacked a group defined control, is possible to analyze the value of the Odds global ratio due to the homogenous behaviour of the studies with defined cases and controls affluent. This demonstrated to association between VPH and the bladder cancer.

Keywords: Bladder cancer. Papillomavirus. Chain reaction of the polymerase.

Abreviaturas: H: Hibridación. CCT: Carcinoma de células transicionales. CCS: Carcinoma de células escamosas. SB-H: Southern blot Hibridación. Ac: Anticuerpos. 
$\mathrm{E}$ carcinoma de vejiga es una enfermedad importante por su morbi-mortalidad y su multifactorialidad. Más del 90\% de las neoplasias vesicales corresponden a carcinomas de células transicionales (CCT), y dentro de este tipo, el patrón papilar superficial representa el $75 \%$. Le siguen en frecuencia el carcinoma de células escamosas (CCS) (5\%) y Adenocarcinoma (0,5\%$2 \%)^{1}$.

Algunos estudios señalan que la infección crónica del tracto urinario, se asocia con el desarrollo del carcinoma vesical, en especial con el CCS, siendo el Schistosoma haemotobium, el agente infeccioso que más frecuentemente se ha relacionado con este tipo celular ${ }^{2}$.

Actualmente, entre los posibles agentes etiológicos que se han señalado está la infección por VPH. La posible asociación entre el VPH y el carcinoma vesical no se ha estudiado de forma importante y sistemática, ya que sólo existen algunos estudios que la analizan de manera parcial. Esta posible relación se basa en el tropismo epitelial del VPH y la proximidad anatómica de la vejiga con la mucosa que recubre el tracto urogenital $^{1}$. La relación entre VPH y los tumores de cérvix se ha estudiado ampliamente (en algunas series, el ADN del VPH se detectó en torno al 95\% de estos tumores) ${ }^{3}$, aunque no se dispone aún de protocolos definitivos de actuación en casos de infección y lesiones histológicamente poco agresivas.

La prevalencia del VPH en sujetos con neoplasias de vejiga, en estudios previos, oscila entre el $0 \%$ y 100\%. Dado este amplio espectro nos encontramos con trabajos que encuentran una estrecha asociación entre el VPH y $\mathrm{CCT}^{4-6}$, mientras que en otros, dicha asociación es mínima o nula ${ }^{7,8}$.

Con la literatura publicada hasta septiembre del 2004 nos proponemos a desarrollar un estudio analítico para filtrar, analizar y reevaluar la información existente hasta la actualidad.

\section{MATERIAL Y MÉTODOS}

Realizamos una búsqueda en la base de datos electrónica MEDLINE de los artículos publicados hasta septiembre del 2004 que relacionan la infección del virus del papiloma humano con los tumores vesicales. Para ello estable- cimos una búsqueda abierta con los términos "Bladder tumour" and "virus". Generalizando de esta forma, conseguimos minimizar posibles errores asociados al primer cribado. De los 414 artículos listados, decidimos desechar: los que no estudian dicha asociación, los que carecían de "abstract" y habían sido publicados en idiomas de difícil traducción, así como los casos clínicos.

Una vez finalizada la búsqueda, se revisa la bibliografía de cada uno de los artículos. Así mismo, de cada nuevo artículo repetimos el protocolo de búsqueda de referencias. De entre todos los artículos, finalmente seleccionamos 38 artículos, publicados en español, inglés y francés, que relacionaban el tumor de vejiga con la infección del virus del papiloma humano.

La revisión sistemática constó básicamente de dos componentes: uno cualitativo, donde se hizo una descripción epidemiológica de los trabajos, actuando los estudios individuales como los sujetos de la investigación; y un componente cuantitativo, el meta-análisis, que se refiere a la agrupación estadística de los resultados, obteniéndose un estimador de efecto único, que combina los efectos observados en los diferentes estudios individuales. Sin duda este último componente, que se refiere puramente a la técnica estadística, es el que refleja de una manera más directa el efecto de una determinada intervención.

Se empleó como estimador de los efectos combinados la OR (IC a 95\%) y como método de combinación el de Der Simonien y Laird ${ }^{9}$.

La heterogeneidad entre estudios se midió mediante el test de Mantel-Haenszel ( $\left.\mathrm{Q}_{\mathrm{exp}}\right)$.

No existió relación entre la exposición a VPH y la presencia de carcinoma de vejiga cuando el intervalo de confianza obtenido contenía la uni$\operatorname{dad}^{10}$.

\section{RESULTADOS}

Los artículos seleccionados se han organizado en dos grandes grupos, según empleen o no métodos basados en la detección de ADN. Destacamos el escaso número de estudios que emplearon un grupo control definido. Las regiones amplificadas fueron diferentes así como los genotipos detectados, siendo el genotipo 16 y 18 los que más frecuentemente fueron detectados. 
Estudios basados en la detección del DNA

En la Tabla 1 se muestra el nombre de los 36 autores, número de casos y controles empleados en cada estudio, muestra utilizada (fundamentalmente CCT), metodología empleada para la detección del ADN y resultados obtenidos.
En el estudio de Oft y cols ${ }^{11}$, se investiga la presencia de ARNm en tumores con ADN del VPH y en el Singlair y $\operatorname{cols}^{12}$, se comparan modificaciones metodológicas para detectar el ADN. En base a esto no se han utilizado para el análisis estadístico posterior.

\section{Tabla 1}

Estudio basados en la detección de ADN

\begin{tabular}{|c|c|c|c|c|c|}
\hline $\begin{array}{l}\text { Referencias } \\
\text { bibliográficas }\end{array}$ & $\begin{array}{l}\text { Número } \\
\text { casos }\end{array}$ & $\begin{array}{l}\text { Tejido } \\
\text { casos }\end{array}$ & $\begin{array}{l}\text { Número } \\
\text { controles }\end{array}$ & Técnica & $\begin{array}{l}\text { Genotipos } \\
\text { estudiados } \\
\text { (región) }\end{array}$ \\
\hline Agliano et al. $1994^{6}$ & 46 & $\mathrm{CCT}$ & $\begin{array}{l}10 \text { (vejiga } \\
\text { normal) }\end{array}$ & $\begin{array}{c}\text { PCR } \\
\text { selectiva + } \\
\text { dot-blot } \\
\text { hibridación } \\
\text { (H) }\end{array}$ & 16 y 18 (E6) \\
\hline Anwar et al. $1992^{5}$ & 48 & $46 \mathrm{CCT}, 2$ (CCS) & $\begin{array}{l}21 \text { (vejiga } \\
\text { normal) }\end{array}$ & $\begin{array}{l}\text { PCR dot- } \\
\text { blot H. + SB-B } \\
\text { (Southern } \\
\text { blot } \\
\text { hibridación) }\end{array}$ & $\begin{array}{c}6,11,16,18 \mathrm{y} \\
33(\mathrm{E} 6)\end{array}$ \\
\hline Aynaud et al. $1998^{22}$ & 57 & $57 \mathrm{CCT}$ & $\begin{array}{l}1 \text { (condiloma } \\
\text { vesical) }\end{array}$ & $\begin{array}{l}\text { SB-H.; PCR } \\
\text { + dot-blot H. }\end{array}$ & $\begin{array}{c}6,11,16,18,31 \\
33,35,39 \text { y } 42 \\
(\mathrm{~L} 1, \mathrm{E} 1, \mathrm{E} 2, \mathrm{E} 6)\end{array}$ \\
\hline Boucher et al. $1996^{23}$ & 55 & 54 CCT y 1 CCS & 0 & $\begin{array}{c}\text { dot-Blot H. } \\
\text { P32 }\end{array}$ & $\begin{array}{l}\text { 6, } 11 \text { y } 16 \text { (no } \\
\text { indicado) }\end{array}$ \\
\hline Bryant et al. $1991^{13}$ & 92 & $\begin{array}{c}66 \text { CCT profundo, } \\
10 \text { CCT } \\
\text { superficial, } \\
2 \text { CCT p/s, } 3 \mathrm{CCS}, 4 \\
\text { Adenocarcinomas, } \\
7 \text { carcinomas } \\
\text { indiferenciados. }\end{array}$ & $\begin{array}{l}8 \text { (3 displasias } \\
5 \text { T. benignos) }\end{array}$ & H. in-situ & $\begin{array}{l}6 \mathrm{~b}, 11,16 \text { y } 18 \\
\text { (no indicado) }\end{array}$ \\
\hline Cooper et al. $1997^{24}$ & 25 & $\mathrm{CCS}$ & 0 & $\begin{array}{l}\text { H. in-situ + } \\
\text { PCR }\end{array}$ & $\begin{array}{c}6,11,16,18,31 \\
\text { y } 33(\mathrm{E} 6)\end{array}$ \\
\hline Chan et al. $1997^{14}$ & 20 & $\mathrm{CCT}$ & $\begin{array}{l}10 \text { (Papiloma } \\
\text { invertido) }\end{array}$ & $\begin{array}{c}\text { PCR } \\
\text { selectiva }+ \\
\text { dot-blot } \mathrm{H} .\end{array}$ & $\begin{array}{c}6,11,16,18,31 \\
\text { y } 33(\mathrm{E} 6)\end{array}$ \\
\hline Chang et al. $1994^{25}$ & 108 & $\mathrm{CCT}$ & 0 & $\mathrm{PCR}+\mathrm{SB}-\mathrm{H}$ & $\begin{array}{c}6,11,16,18,31 \\
33,35,39,40 \\
45,51 \text { y } 59 \text { (L1) }\end{array}$ \\
\hline Chetsanga et al. $1992^{26}$ & 44 & $\mathrm{CCT}$ & 0 & $\begin{array}{c}\text { PCR + } \\
\text { dot-blot } \mathrm{H} .\end{array}$ & Genérico (L1) \\
\hline Furihata et al. $1993^{27}$ & 90 & $\mathrm{CCT}$ & 0 & H. in-situ & $\begin{array}{c}\text { 16, } 18 \text { y } 33 \text { (no } \\
\text { indicado) }\end{array}$ \\
\hline De Gaetani et al. $1999^{28}$ & 43 & $\mathrm{CCT}$ & 0 & H. in-situ & $\begin{array}{l}6 / 11,16 / 18 \\
31 / 33 / 35 \text { (no } \\
\text { indicado) }\end{array}$ \\
\hline Gazzaniga et al. $1998^{15}$ & 35 & $\mathrm{CCT}$ & $\begin{array}{l}10 \text { (vejiga } \\
\text { normal) }\end{array}$ & $\begin{array}{l}\text { PCR + dot- } \\
\text { blot H. }\end{array}$ & $\begin{array}{l}16 \text { y } 18 \text { (no } \\
\text { indicado) }\end{array}$ \\
\hline Gopalkrishna et al. $1995^{29}$ & 10 & $\mathrm{CCT}$ & 0 & $\begin{array}{l}\text { H. in-situ + } \\
\text { PCR }\end{array}$ & $\begin{array}{l}16 \text { (región } \\
\text { reuladora } \\
\text { upstream) }\end{array}$ \\
\hline Tekin et al. $1999^{16}$ & 42 & $\mathrm{CCT}$ & $\begin{array}{l}10 \text { (vejiga } \\
\text { normal) }\end{array}$ & $\begin{array}{c}\text { PCR } \\
\text { selectiva }\end{array}$ & 16 y $18(\mathrm{~L} 1)$ \\
\hline Khaled et al. $2003^{4}$ & 99 & No indicado & 0 & $\begin{array}{l}\text { PCR general; } \\
\text { PCR tipo } \\
\text { específica }\end{array}$ & $\begin{array}{c}6,11,16,18 \mathrm{y} \\
33 \text { (L1) }\end{array}$ \\
\hline
\end{tabular}




\begin{tabular}{|c|c|c|c|c|c|}
\hline Khaled et al. $2001^{30}$ & 50 & $\begin{array}{c}23 \text { CCS, } 22 \text { CCT, } 3 \\
\text { adenocarcinomas, } \\
7 \text { carcinomas } \\
\text { indiferenciados. }\end{array}$ & 0 & H. in-situ & $\begin{array}{l}16 / 18 \text { (no } \\
\text { indicado) }\end{array}$ \\
\hline Kamel et al. $1995^{31}$ & 47 & $40 \mathrm{CCT}, 7 \mathrm{CCS}$ & 0 & H. in-situ & $\begin{array}{c}6,11,16,18,31 \\
\text { y } 33 \\
\text { (no indicado) }\end{array}$ \\
\hline Kitamura et al. $1988^{32}$ & 10 & $\begin{array}{c}9 \mathrm{CCT}, 1 \\
\text { adenocarcinoma }\end{array}$ & 3 (cistitis) & $\begin{array}{c}\mathrm{PCR}+ \\
\text { dot-blot H. }\end{array}$ & 16 (no indicado) \\
\hline Knowles et al $1992^{18}$ & 120 & $\begin{array}{c}100 \mathrm{CCT}, 6 \\
\text { carcinomas in situ, } 2 \\
\text { adenocarcinomas, } 1 \mathrm{CCS}, \\
11 \text { carcinomas } \\
\text { indiferenciados }\end{array}$ & 0 & $\mathrm{PCR}+\mathrm{SB}-\mathrm{H}$ & $\begin{array}{c}5,8,11,16,18 \mathrm{y} \\
33(\mathrm{E} 1, \mathrm{~L} 1)\end{array}$ \\
\hline López- Beltrán et al. $1996^{20}$ & 76 & CCT & 0 & H. in-situ & $\begin{array}{c}6 / 11,16 / 18 \mathrm{y} \\
31 / 33 / 35 \\
\text { (no indicado) }\end{array}$ \\
\hline López-Beltrán et al. $1996^{33}$ & 76 & $\mathrm{CCT}$ & 0 & $\mathrm{PCR}+\mathrm{SB}-\mathrm{H}$ & $\begin{array}{c}6,11,16 \text { y } 18 \\
(\mathrm{~L} 1, \mathrm{E} 5, \mathrm{E} 6)\end{array}$ \\
\hline López-Beltrán et al. $1995^{34}$ & 76 & $\mathrm{CCT}$ & 0 & PCR + h. in-situ & $\begin{array}{c}6 / 11,16 / 18 \mathrm{y} \\
31 / 33 / 35 \\
(\mathrm{~L} 1, \mathrm{E} 5, \mathrm{E} 6)\end{array}$ \\
\hline Lu et al. $1997^{7}$ & 31 & $\begin{array}{c}22 \mathrm{CCT}, 4 \\
\text { adenocarcinomas, } \\
5 \mathrm{CCS}\end{array}$ & $\begin{array}{c}41 \text { (32 vejiga } \\
\text { normal } \\
9 \text { cistitis } \\
\text { crónicas) }\end{array}$ & H. in-situ & $\begin{array}{l}16 \text { y } 18 \text { (no } \\
\text { indicado) }\end{array}$ \\
\hline Ludwing et al. $1996^{17}$ & 23 & $\begin{array}{c}21 \mathrm{CCT}, 1 \\
\text { adenocarcinomas, } \\
1 \mathrm{CCS}\end{array}$ & 0 & $\begin{array}{l}\text { PCR } \\
\text { PCR }\end{array}$ & $\begin{array}{c}6 \mathrm{~b}, 11,16 \text { y } 18 \\
(\mathrm{~L} 1)\end{array}$ \\
\hline Maloney et al. $1994^{35}$ & 42 & $22 \mathrm{CCS}, 20 \mathrm{CCT}$ & 0 & $\begin{array}{c}\text { PCR } \\
\text { selectiva }\end{array}$ & $\begin{array}{c}6 \mathrm{~b}, 11,13,16, \\
18,31,32,33, \\
35,45 \text { y } 51(\mathrm{~L} 1, \\
\text { E6) }\end{array}$ \\
\hline Mvula et al. $1996^{36}$ & 36 & $34 \mathrm{CCT}, 2 \mathrm{CCS}$ & 2 & $\begin{array}{c}\text { PCR } \\
\text { selectiva }\end{array}$ & $\begin{array}{c}6,11,16,18,31 \\
33,42,52 \text { y } 58 \\
\text { (L1, E7) }\end{array}$ \\
\hline Noel et al. $1994^{37}$ & 2 & CCT & $\begin{array}{l}2 \text { (vejiga } \\
\text { normal) }\end{array}$ & $\begin{array}{c}\text { PCR } \\
\text { selectiva }\end{array}$ & $\begin{array}{c}6 \mathrm{~b}, 11,16 \text { y } 18 \\
(\mathrm{E} 7)\end{array}$ \\
\hline Oft et al. $1993^{11}$ & 1 & $1 \mathrm{CCS}$ & 0 & $\begin{array}{l}\text { PCR } \\
\text { diferencial; } \\
\text { H. in situ P32 } \\
\text { ARNm de } \\
\text { región E7 }\end{array}$ & $6(\mathrm{~L} 1, \mathrm{E} 6)$ \\
\hline Olsen et al. $1995^{38}$ & 1 & $\mathrm{CCT}$ & 0 & PCR +H. in-situ & $\begin{array}{c}6 / 11,16,18 \text { y } 31 \\
\text { (CP-Is, CP-G) }\end{array}$ \\
\hline Saltzstein et al. $1993^{39}$ & 33 & CCT & $\begin{array}{c}2 \text { (1 displasia, } \\
1 \text { tej. }\end{array}$ & $\mathrm{PCR}+\mathrm{SB}-\mathrm{H}$ & $\begin{array}{c}6,11,16,18,31 \\
\text { y } 33(\mathrm{~L} 1, \mathrm{E} 1)\end{array}$ \\
\hline Shibutani et al. $1992^{40}$ & 21 & $20 \mathrm{CCT}, 1 \mathrm{CCS}$. & 0 & SB-H. & $\begin{array}{c}6 / 11,16 / 18 \\
31 / 33(\mathrm{~L} 1)\end{array}$ \\
\hline Simoneau et al. $1999^{41}$ & 187 & CCT & 0 & $\begin{array}{l}\text { PCR + SB-H } \\
\text { or dot-blot H. }\end{array}$ & $\begin{array}{c}6,11,16,18 \mathrm{y} \\
33(\mathrm{~L} 1)\end{array}$ \\
\hline Singlair et al. $1993^{12}$ & 14 & $\begin{array}{c}13 \text { CCT, } \\
1 \text { carcinoma de } \\
\text { células claras }\end{array}$ & 0 & $\begin{array}{c}\text { PCR } \\
\text { selectiva }\end{array}$ & 6,11 y $16(\mathrm{~L} 1)$ \\
\hline Sur et al. $2001^{42}$ & 64 & CCT & 0 & PCR +H. in-situ & $\begin{array}{c}6,11,16,18,31 \\
\text { y } 33(\mathrm{~L} 1)\end{array}$ \\
\hline Westenend et al. $2001^{8}$ & 16 & $\mathrm{CCS}$ & 0 & H. in-situ & $\begin{array}{c}6 / 11,16 / 18 \text { y } \\
31 / 33 / 51 \\
\text { (no indicado) }\end{array}$ \\
\hline Wilczynski et al. $1993^{43}$ & 22 & $\mathrm{CCS}$ & 0 & PCR + SB-H. & $\begin{array}{c}6,11,16 \text { y } 18 \\
\text { (L1, E7) }\end{array}$ \\
\hline
\end{tabular}


En la mayoría de los casos se usó la PCR, aunque solo en $10(27,7 \%)$ emplean controles internos de extracción del ADN y amplificación genética y solamente 7 (19,44\%) utilizaron biopsias de tejido congelado. De su estudio resultó que la proporción global de los casos que tuvieron contacto con el virus, a través de la detección del genoma fue del 19,4\% (IC 95\%: 0,1600,228). Además el valor de Qexp (Gexp: 621,04, $33 \mathrm{gl}, \mathrm{p}<0,001)$ informa de una importante dispersión de los resultados obtenidos entre los estudios.

Cuando se aplica este mismo análisis separando los estudios que emplean la prueba de PCR (26) resulta que, la proporción global de los casos que tuvieron contacto con el virus fue del 18,9\% (IC 95\%: 0,152-0,227). Además el valor de Qexp (Qexp: 440,04, 23 g1, p<0,001) informa de una importante dispersión de los resultados obtenidos.

De la misma forma, en los 10 estudios en los que no emplean la PCR, la proporción global de los casos que tuvieron contacto con el virus fue del 21,5\% (IC 95\%: 0,119-0,310). El valor de Qexp (Qexp: 161,27, 9 gl, p<0,001) informa de una importante dispersión de los resultados obtenidos. En estos estudios, la prevalencia del VPH en sujetos con tumor de vejiga oscila entre el 0 y $100 \%$.

Del total de estudios basados en la detección del ADN (mediante PCR u otra técnica) se seleccionaron 8 (en 7 utilizan la PCR y tan solo en 1 la Hibridación in situ) por mostrar un grupo control definido, y en los cuales se investigó la $O R^{5,6,13-18}$. El valor de $\mathrm{Qexp}$ (Qexp: 14,49, 7 gl, p: 0,1517) informa de una escasa dispersión de los resultados obtenidos. Si combinamos las ORs, empleando el método de Der Simonien y Laird $^{9}$, obtenemos un valor de OR estimada de 3,2 (IC al 95\% de 1,19 a 8,60) y una $\mathrm{p}=0,02$. Esto indica que existe una clara asociación entre la exposición al virus determinada mediante la detección del ADN y el cáncer vesical (Tabla 2).

Tabla 2
Estudios no basados en la detección del DNA

En la Tabla 3, se muestra el nombre de los 4 autores, número de casos y controles empleados en cada estudio, muestra utilizada, metodología empleada para la detección del VPH. De estos estudios, 3 (75\%) investigan el antígeno capsídico del virus ${ }^{19-21}$ y 1 determina los anticuerpos (Ac) en suero ${ }^{17}$. De su estudio resultó que la proporción global de los casos que tuvieron contacto con el virus, a través de la detección del antígeno o los anticuerpos, fue del 22,2\% (IC 95\%: 0,1140,330). Además el valor de Qexp (Qexp:6,87, 3 gl, p:0,076) informa de una importante dispersión de los resultados obtenidos entre los estudios.

\section{DISCUSIÓN}

Hasta la fecha, se han caracterizado más de 100 genomas completos del VPH, de los que sólo algunos, integran su $\mathrm{ADN}$ en el genoma de la célula huésped. Precisamente, basándose en sus propiedades de integración y en su diferente tendencia a asociarse con procesos benignos o carcinomas invasores, los VPH se han clasificado en tipos de "bajo riesgo" (6 y 11) y en tipos de "alto riesgo" (16 y 18) ${ }^{3}$.

El carcinoma vesical, en sus distintos tipos histológicos, es una entidad clínica de la cual se desconocen ciertos aspectos como: 1) si existe un factor genético que determine su predisposición (aunque hay implicados varios oncogenes), 2) cual es el principal factor de riesgo implicado en su génesis, lo cual nos impide ejercer una cam-

Estudios basados en la detección de ADN

\begin{tabular}{|c|c|c|c|c|}
\hline Autores & OR & IC $95 \%$ & $\mathbf{Z}$ & $\mathbf{P}$ \\
\hline Agliano et al. $1994^{6}$ & 20,00 & $1,10->$ & 2,03 & 0,04279 \\
\hline Anwar et al.. $1992^{5}$ & 8,67 & 2,71 a 27,68 & 3,64 & 0,00027 \\
\hline Bryant et al. $1991^{13}$ & 2,40 & 0,13 a 44,54 & 0,59 & 0,55689 \\
\hline Chan et al. $1997^{14}$ & 0,80 & 0,16 a 4,8 & 0,27 & 0,789438 \\
\hline Gazzaniga et al. $1998^{15}$ & 16,84 & $0,91->$ & 1,90 & 0,05778 \\
\hline Tekin et al. $1999^{16}$ & 1,00 & 0,04 a 23,94 & 0,00 & 1,00000 \\
\hline Knowles et al. $1992^{18}$ & 0,03 & 0,00 a 1,48 & 1,77 & 0,07666 \\
\hline Ludwing et al. $1996^{17}$ & 4,47 & 1,00 a 20,02 & 1,96 & 0,05027 \\
\hline $\begin{array}{l}\text { Odds ratio global } \\
\text { (DerSimonien- Laird, 1986) }\end{array}$ & 3,20 & 1,19 a 8,60 & 2,30 & 0,02141 \\
\hline Heterogeneidad $\mathrm{Q}: 14,49$ & & & & \\
\hline
\end{tabular}


Tabla 3

Estudios no basados en la detección del ADN

\begin{tabular}{|c|c|c|c|c|c|}
\hline $\begin{array}{l}\text { Referencias } \\
\text { bibliográficas }\end{array}$ & $\begin{array}{l}\text { Número } \\
\text { casos }\end{array}$ & $\begin{array}{l}\text { Tejido } \\
\text { casos }\end{array}$ & $\begin{array}{l}\text { Número } \\
\text { controles }\end{array}$ & Técnica & Antigeno \\
\hline Bryant et al. $1987^{19}$ & 50 & $\begin{array}{c}16 \mathrm{CCS}, \\
2 \mathrm{CCT} \\
\text { superficial, } 32 \\
\text { CCT profundo }\end{array}$ & 0 & $\begin{array}{c}\text { Inmunoperoxidasa } \\
\text { Ac BPV-1 }\end{array}$ & Cápside \\
\hline Ludwing et al. $1996^{17}$ & 23 & $\begin{array}{c}21 \mathrm{CCT}, 1 \\
\text { adenocarcinoma } \\
1 \mathrm{CCS}\end{array}$ & $\begin{array}{c}41 \text { (32 vejiga } \\
\text { normal, } 9 \\
\text { cistitis crónica }\end{array}$ & $\begin{array}{c}\text { Western Blot para } \\
\text { buscar Ac }\end{array}$ & $\begin{array}{c}6 \text { b (11-L2), } \\
16 \text { (L2-E4-E7) y } \\
18 \text { (L2-E7) }\end{array}$ \\
\hline Roussel et al. $1991^{21}$ & 6 & $\mathrm{CCT}$ & 0 & Inmunoperoxidasa & Cápside \\
\hline
\end{tabular}

paña de prevención eficaz. En nuestro estudio, nos hemos propuesto conocer algo más acerca del posible factor ambiental que actuaría como cofactor en el desarrollo de la enfermedad, por lo que decidimos estudiar el virus del papiloma humano, el cual ha sido mencionado en la bibliografía como posible agente etiológico. Elegimos el meta-análisis como herramienta estadística debido a su enorme versatilidad, su capacidad de aprovechamiento de la información y la facilidad en su interpretación. Los resultados obtenidos resultan esperanzadores ya que de los ocho estudios seleccionados, del total de basados en la detección del ADN, se obtuvo una OR conjunta de 3,2 , lo cual nos permite concluir que existe una clara asociación entre la exposición al virus y la presencia de carcinoma vesical, similar a la encontrada por otro meta-análisis ${ }^{44}$. Para la interpretación de los resultados del meta-análisis hemos de tener en cuenta, sobre todo la significación estadística del análisis o intervalo de confianza de cada artículo del grupo estudiado, así como la odds ratio. De esta forma, consideramos que no existen diferencias significativas entre enfermedad y agente en un tipo de muestra concreto siempre que el intervalo de confianza, al 95\%, arroje un resultado que contenga la unidad. Por tanto, un intervalo por encima o por debajo de este valor indicará una posible relación entre ambas variables. El valor de las Qexp obtenidas del análisis de los estudios tanto no basados en el ADN como basados en el ADN, y dentro de ellos aquellos que utilizaron la PCR como método para la detección del genoma del virus como de los que utilizaron otro método diferente a la PCR, nos informa de una importante dispersión de los datos obtenidos, lo cual nos obligó a centrarnos solo en ocho artículos, los cuales contaban con un grupo control definido y una escasa dispersión de los resultados, para obtener una $O R$ global que nos permitiera llegar a la conclusión expuesta anteriormente. En algunos casos, el nivel de significancia y el peso no concuerdan entre si. Esto es debido a que no existe, como ya hemos comentado, homogeneidad entre los parámetros analizados en todos los artículos, ya que cada autor utiliza un número distinto de casos y controles (y la mayoría ninguno). Esta situación es contemplada por el meta-análisis y no influye en el cálculo de los resultados sino que es meramente informadora.

\section{CONCLUSIONES}

Hasta septiembre del 2004 sólo 36 estudios habían analizado la relación entre VPH y el cáncer de la vejiga. La metodología empleada fue diferente, con un predominio de los estudios que utilizan la PCR. La mayor parte de estos estudios pusieron de manifiesto la relación planteada al inicio del estudio VPH. Aunque la mayor parte carecieron de un grupo control definido, es posible analizar el valor de la Odds ratio global debido al comportamiento homogéneo de los estudios con casos y controles bien definidos. Esto demostró una asociación entre VPH y el cáncer de la vejiga. Dicho hallazgo, depende del método empleado; por tanto para obtener una conclusión definitiva falta en la literatura analizada un estudio con suficiente número de casos y muestras, 
comparativo frente a controles y que utilice la combinación de varias técnicas microbiológicas en un mismo sujeto y muestra.

Otro aspecto a tener en cuenta es que un número importante de artículos no hacen referencia al grado histológico ni estadio tumoral (clasificación TNM), por lo que no se pueden establecer conclusiones sobre si el VPH influye en el grado o estadio tumoral, lo cual, invita a seguir investigando la relación entre el virus y este tumor a través de estudios patogénicos de la enfermedad.

\section{REFERENCIAS}

1. Varig MR, Hajimohammadmehdiarbab A, Hossein Moghaddam SSM, Kazemi B. Correlation between human papillomavirus infection and bladder transitional cell carcinoma. BMC Infect Dis. 2005;5(8): 102.

2. El-Gabry EA, Strup SE, Gomella LG. El cáncer superficial de vejiga: epidemiología, diagnóstico e historia natural. AUA Update Series. Ed. Española. 2001;1(2):85-108.

3. Youshya S, Purdie K, Breuer J, Proby C, Sheaf MT, Oliver RT, et al. Does human papillomavirus play a role in the development of bladder transitional cell carcinoma? A comparison of PCR and immunohistochemical analysis. J Clin Pathol. 2005;58(2):207-210.

4. Khaled HM, Bahnassi AA, Zekri AR, Kassem HA, Mokhtar N. Correlation between p53 mutations and VPH in bilharzial bladder cancer. Urol Oncol. 2003;21(5):334-341.

5. Anwar K, Naiki H, Nakakuki K, Inuzuka M. High frequency of human Papillomavirus infection in carcinoma of the urinary bladder. Cancer. 1992;70(7):1967-1973.

6. Agliano AM, Gradilone A, Gazzaniga P, Napolitano M, Vercillo R, Albonici L, et al. High frequency of human Papillomavirus detection in urinary bladder cancer. Urol Int. 1994; 53(3):125-129.

7. Lu QL, Lalani N, Abel P. Human Papillomavirus 16 and 18 infection is absent in urinary bladder carcinomas. Eur Urol. 1997;31(4):428-432.

8. Westenend PJ, Stoop JA, Hendriks JG. Human Papillomaviruses $6 / 11,16 / 18$ and $31 / 33 / 51$ are not associated with squamous cell carcinoma of the urinary bladder. $\mathrm{Br} \mathrm{J}$ Urol Int. 2001;88(3):198-201.

9. DerSimonian R, Laird N. Meta-analysis in clinical trial. Control Clin Trials. 1986;7(3):177-188.

10. Egger M, Smith GP, Altman DG. Systematic Reviews in Health Care. Meta-Analysis Context. London, United Kingdom: BMJ Bookshop, 1995.

11. Oft M, Bohm S, Wilczynski SP, Iftner T. Expression of the different viral mRNAs of human papilloma virus 6 in a squamous-cell carcinoma of the bladder and the cervix. Int J Cancer. 1993;53(6):924-931.

12. Singlair AL, Nouri AM, Oliver RT, Sexton C, Dalgleish AG. Bladder and prostate cancer screening for human papillomavirus by polymerase chain reaction: conflicting results using different annealing temperatures. Br J Biomed Sci. 1993; 50(4):350-354.

13. Bryant P, Davies P, Wilson D. Detection of human Papillomavirus DNA in cancer of the urinary bladder by in situ hybridisation. Br J Urol. 1991;68(1):49-52.
14. Chan KW, Wong KY, Srivastava G. Prevalence of six types of human Papillomavirus in inverted papilloma and papillary transitional cell carcinoma of the bladder: an evaluation by polymerase chain reaction. J Clin Pathol. 1997; 50(12): 1018-1021.

15. Gazzaniga P, Vercillo R, Gradilone A, Silvestre I, Gandini O, Napolitano N, et al. Prevalence of Papillomavirus, Epstein-Barr virus, Cytomegalovirus, and Herpes Simplex virus type 2 in urinary bladder cancer. J Med Virol. 1998; 55(4):262-267.

16. Tekin MI, Tuncer S, Aki FT, Bilen CY, Aygun C, Ozen H. Human Papillomavirus associated with bladder carcinoma?. Analysis by polymerase chain reaction. Int $\mathrm{J}$ Urol. 1999;6(4): 184-186.

17. Ludwing M, Kochel HG, Fischer C, Ringert RH, Weidner W. Human Papillomavirus in tissue of Bladder and Bladder carcinoma specimens. Eur Urol. 1996;30(1):96-102.

18. Knowels MA. Human Papillomavirus sequences are not detectable by Southern blotting or general primer-mediated polymerase chain reaction in transitional cell tumours of the bladder. Urol Res 1992;20(4):297-301.

19. Bryant P, Skelly J, Wilson D. Demonstration of papillomavirus structural antigen in human urinary bladder neoplasia. Br J Urol. 1987;60(5):405-409.

20. López-Beltran A, Escudero AL, Carrasco-Aznar JC, Vicioso-Recio L. Human Papillomavirus infection and transitional cell carcinoma of the bladder. Pathol Res Pract. 1996;192(2):154-159.

21. Roussel F, Picquenot JM, Rousseau O. Identification of human Papillomavirus Antigen in a Bladder tumor. Acta Cytol. 1991;35(3):273-276.

22. Aynaud O, Tranbaloc P, Orth, G. Lack of evidence for a role of human papillomaviruses in transitional cell carcinoma of the bladder. J Urol. 1998;159(1):86-89.

23. Boucher NR, Scholefield J H, Anderson J.B. The aetiological significance of human papillomavirus in bladder cancer. Br J Urol. 1996;78(6):866-869.

24. Cooper, K., Haffajee, Z. and Taylor, L. Human papillomavirus and schistosomiasis associated bladder cancer. Mol Pathol. 1997;50(3): 145-148.

25. Chang F, Lipponen P, Tervahauta A, Syrjanen S, Syrjanen K. Transitional cell carcinoma of the bladder: failure to demonstrate human papillomavirus deoxyribonucleic acid by in situ hybridization and polymerase chain reaction. $J$ Urol. 1994;152(5): 1429-1433.

26. Chetsanga C, Malmstrom PU, Gyllensten U, MorenoLopez J, Dinter Z, Pettersson U. Low incidence of human papillomavirus type 16 DNA in bladder tumor detected by the polymerase chain reaction. Cancer. 1992;69:12081211 .

27. Furhiata M, Inoue K, Ohtsuki Y, Hashimoto H, Terao N, Fujita Y. High-risk human Papillomavirus infections and overexpression of p53 protein as prognostic indicators in transitional cell carcinoma of the urinary bladder. Cancer Res. 1993;53:4823-4827.

28. De Gaetani C, Ferrari G, Righi E, Bettelli S, Migaldi M, Ferrari P, et al. Detection of human Papillomavirus DNA in urinary bladder carcinoma by in situ hybridisation. J Clin Pathol.1999;52(2):103-106.

29. Gopalkrishna V, Srivastava AN, Hedau S, Sharma JK, Das BC. Detection of human Papillomavirus DNA sequences in cancer of the urinary bladder by in situ hybridisation and polymerase chain reaction. Genitourin Med. 1995;71(4): 231-233. 
30. Khaled HM, Raafat A, Mokhtar N, Zekri AR, Gaballah H. Human Papilloma virus infection and overexpression of p53 protein in Bilharzial Bladder cancer. Tumori. 2001;87(4):256-261.

31. Kamel D, Paakko P, Pollanen R, Vahakangas K, Lehto VP, Soini Y. Human Papillomavirus DNA and abnormal p53 expression in carcinoma of the Urinary Bladder. APMIS. 1995;103(5):331-338.

32. Kitamura T, Yogo Y, Ueki T, Murakami S, Aso Y. Presence of human Papillomavirus type 16 genome in Bladder carcinoma in situ of a patient with mild immunodeficiency. Cancer Res. 1988;48(24):7207-7211.

33. López-Beltrán A, Escudero AL, Vicioso L, Muñoz E, Carrasco JC. Human Papillomavirus DNA as a factor determining the survival of bladder cancer patients. $\mathrm{Br} \mathrm{J}$ Cancer. 1996;73(1):124-127.

34. López-Beltran A, Muñoz E. Transitional cell carcinoma of the Bladder: low incidence of human Papillomavirus DNA detected by polymerase chain reaction and in situ hybridization. Histopathology. 1995;26(6):565-569.

35. Maloney KE, Wiener JS, Walther PJ. Oncogenic human Papillomaviruses are rarely associated with squamous cell carcinoma of the Bladder: evaluation by differential polymerase chain reaction. J Urol. 1994;151(2):360-364.

36. Mvula M, Iwasaka T, Iguchi A, Nakamura S, Masaki Z, Sugimori H. Do human Papillomaviruses have a role in the pathogenesis of Bladder carcinoma?. J Urol. 1996;155(2): 471-474.

37. Noel JC, Peny MO, Mat O, Antoine M, Firket C, Detremmerie O, et al. Human Papillomavirus type 16 associated with multifocal transitional cell carcinomas of the 38. Bladder in two transplanted patients. Transpl Int. 1994;7(5):340-343.

38. Olsen S, Marcussen N, Jensen KM, Lindeberg H. Urethral condylomata, due to human papilloma virus (VPH) type
6/11, associated with transitional cell tumors in the bladder and ureter. A case report. Scand J Urol Nephrol Suppl. 1995;172:51-55.

39. Saltzstein DR, Orihuela E, Kocurek JN, Payne DA, Chan TS, Tyring SK. Failure of the polymerase chain reaction (PCR) to detect human Papillomavirus (VPH) in transitional cell carcinoma of the Bladder. Anticancer Res. 1993;13(2):423-426.

40. Shibutani YF, Schoenberg MP, Carpiniello VL, Malloy TR. Human Papillomavirus associated with Bladder cancer. Urology. 1992;40(1):15-17.

41. Simoneau M, LaRue H, Fradet Y. Low frequency of human papillomavirus infection in initial Papillary Bladder tumors. Urol Res. 1999;27(3):180-184.

42. Sur M, Cooper K, Allard U. Investigation of human Papillomavirus in transitional cell carcinomas of the Urinary Bladder in South Africa. Pathology. 2001;33(1):1721.

43. Wilczynski SP, Oft M, Cook N, Liao SY, Iftner T. Human Papillomavirus type 6 in squamous cell carcinoma of the Bladder and cervix. Human Pathol. 1993;24(1):96-102.

44. Gutiérrez J, Jiménez A, De Dios Luna J, Soto MJ, Sorlózano A. Meta-analysis of studies analyzing the relationship between bladder cancer and infection by human papillomavirus. J Urol. 2006;176(6):2474-2481.

Correspondencia autor: Dr. A. Jiménez Pacheco Servicio de Urología. Hospital Universitario San Cecilio. Avda. del Doctor Olóriz, 16. 18012 Granada Tel.: 958023084

E-mail autor: anjipa29@hotmail.com

Información del artículo: Original - Cáncer vesical

Trabajo recibido: noviembre 2006

Trabajo aceptado: diciembre 2006 